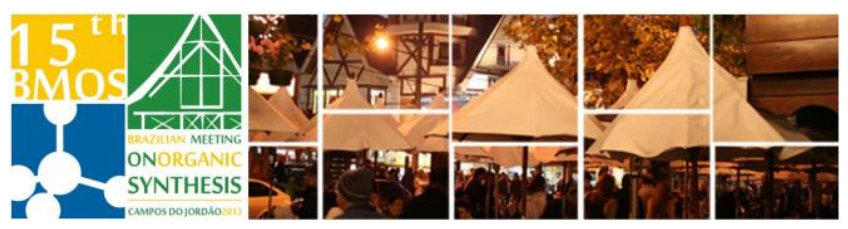

\title{
Synthesis and spectroscopic characterization of urea/thiourea derivatives for potential optical sensors application
}

\section{Claudia Brito da Silva* and Fabiano Severo Rodembusch}

Institute of Chemistry, Federal University of Rio Grande do Sul, Avenida Bento Gonçalves, 9500, Campus do

Vale, 91501-970 Porto Alegre-RS, Brazil

*claudiabritto.silva@gmail.com

Keywords: benzazoles, chemosensors, fluorescence

\section{INTRODUCTION}

The increase of diversity and quantity of metallic ions released into the environment from domestic or industrial untreated waste demands its identification and quantification. Thus, the synthesis of chemosensors for detecting ions has emerged in the past decade, ${ }^{1}$ where several fluorescent organic dyes have been synthesized as optical sensors for metal ions in solution. ${ }^{2}$ The detection of these metals may be based on the increase/decrease of the fluorescence intensity ${ }^{3}$ or even the fluorescence maximum displacement. ${ }^{4}$ In this way, this work reports the synthesis and photophysical characterization of new urea/thiourea compounds as potential optical sensors in solution.

\section{RESULTS AND DISCUSSION}

\section{Synthesis of urea/thiourea derivatives}

The isothiocyanate precursor (2) was obtained from the reaction of p-aminobenzoic acid (1) with equimolar amount of thiophosgene in dry acetone. This product was used without further purification. Compound (3), which precipitates in the reaction mixture, was obtained reacting compound (1) and (2) in DMSO. The benzazole derivatives (6) and (7) were obtained by condensation reaction of the ortosubstituted aniline (4) and (5) with (3) in polyphosphoric (PFA) acid for $5 \mathrm{~h}$.

Scheme 1. Synthetic methodology for obtention of (6-7).

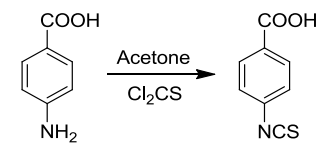

(1)

(2)

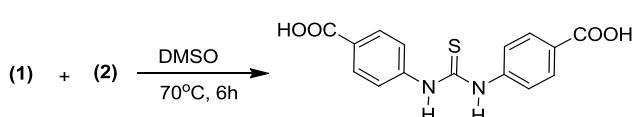

${ }_{(3)}{ }^{\mathrm{H}}$

(3) +

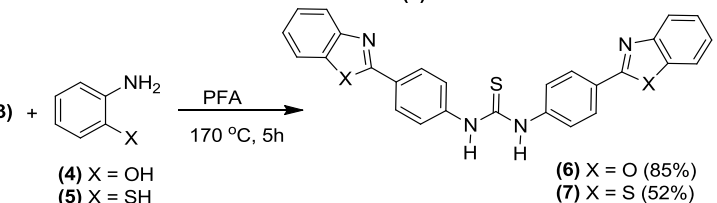

The compounds (10) and (11) were synthesized by the reaction of diphenyldiisocyanate (8) with $p$-amino benzoic acid (1) and 4,4'-oxydianiline (9) with the isothiocyanate benzoic acid (2), respectively.

Scheme 2. Synthetic methodology for obtention of (10-11).

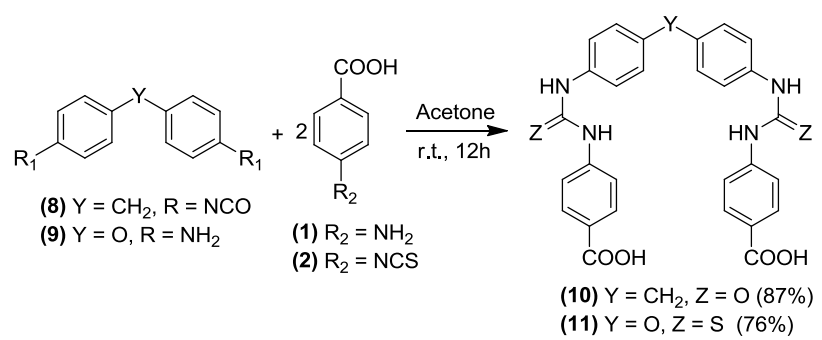

The products were obtained in good yields. ${ }^{1} \mathrm{H},{ }^{13} \mathrm{C}$ NMR and FTIR analysis are consistent with the expected structures of the compounds. Preliminar results indicate that these compounds present absorption in the UV region and emission in the UVvisible regions.

\section{CONCLUSION}

New photoactive urea/thiourea derivatives were successfully obtained with good yields by simple synthetic methodologies. These compounds will be tested as chemosensors for metallic ions in solution and the results will be reported elsewhere. ${ }^{5}$

\section{ACKNOWLEDGEMENTS}

The authors thank CAPES/REUNI, CNPq and INDISaúde for financial support and scholarship.

\section{REFERENCES}

1. Xiang, Y.; Li, Z.; Chen, X.; Tong, A. Talanta 2008, 74 11481153.

2. Kondo, S.; Nagamine, M.; Karasawa, S.; Ishihara, M.; Unno,

M.; Yano, Y.Tetrahedron. 2011, 67, 943-950.

3. Kim, K.; Choi, S. H.; Jeon, J.; Lee, H. ; Huh, J. O. ; Yoo, J. ; Kim, J. T.; Lee, C.H.; Lee, Y. S.; Churchill, D. G. Inorg. Chem. 2011, 50, 5351-5360.

4. Gunnlaugsson, T.; Lee, T. C.; Parkesh, R. Tetrahedron 2004, 60, 11239-11249.

5. kumara, V.; Kaushika, M. P.; Srivastava, A. K.; AjayPratapa, V.; Thiruvenkatam.; Guru Row, T. N. Anal. Chim. Acta. 2010, 663, 77-84. 